\title{
城市建设对暴雨内涝空间分布的影响研究 以武汉市主城区为例
}

\author{
赵丽元,韦佳伶 \\ (华中科技大学建筑与城市规划学院, 武汉 430074)
}

\begin{abstract}
摘 要: 城市内涝灾害频繁, 用地开发与空间扩张被普遍认为是其致因之一。对比武汉市遥感数据, 1984-2017 年, 超过 $30 \%$ 的自然水体被填占开发, 城市建设开发活跃、填湖造陆强度大。论文以武汉市为例, 采用二项 Logistic 模型, 定量分析不同降雨强度情景下的内涝影响因素。研究表明, 填湖造陆将极大地增加极端降雨情景下城市滨 水区域的内涝风险。城市地形地势、排水管网条件、用地类型以及邻域用地结构等因素,也直接影响内涝风险。基 于 2 种不同的用地开发策略, 预测城市内涝风险结果显示, 城市用地的不当开发将引致严重内涝风险。依据内涝 风险的空间分布预测结果, 论文提出了相应的改善策略, 以为科学地制定防涝减灾规划提供参考。
\end{abstract}

关 键 词: 城市内涝; 空间分布; 城市建设; 二项 Logistic 模型

城市内涝是因短时强降水或过程雨量偏大造 成地表径流过多,在地势低洼、排水不畅等情况下 形成积水的自然灾害。近年来, 中国多个大城市的 暴雨洪水与内涝灾害频发, 城市内涝防治已成为公 众普遍关注的重大问题。住建部及水利部数据显 示, 2007-2015 年, 全国超过 360 个城市遭遇内涝, 其中 $1 / 6$ 单次内涝淹水时间超过 $12 \mathrm{~h}$, 淹水深度超 过 $0.5 \mathrm{~m} 。 2010$ - 2016年, 中国平均每年有超过 180 座城市进水受淹或发生内涝。在气候变化下极端 天气频现与城市雨岛效应的双重作用下, 内涝灾害 常发生在人口密集的高度城市化地区, 加剧了对人 们生产生活的危害, 包括巨额的经济损失、对公共 健康与安全的威胁等 ${ }^{[1]}$ 。

因此, 探究内涝成因机制及其应对策略成为研 究热点 ${ }^{[2-5]}$ 。影响城市内涝风险的因素可以分为自 然因素和人文因素 ${ }^{[6-8]}$ 。自然因素主要包括气候特 征、降雨量、土壤性质、地形地势以及水文气象条件 等。人文因素则包括用地结构、用地变化、排水管 网条件、不透水面分布等 ${ }^{[9-1]}$ 。

当前研究主要侧重人文因素, 并已取得较为丰
富的成果。在用地结构方面, 以韩国首尔为案例, Lee 等 ${ }^{[7]}$ 的研究表明: 不透水面和农业用地的成片布 局会加剧内涝灾害程度, 且紧凑高密度的用地布局 一定程度上会阻碍雨水排放。而城市绿地空间在减 缓雨水径流、降低洪涝风险方面具有重要作用 ${ }^{[12]}$ 。 对城市内涝与土地利用结构和景观格局之间的关 系研究 ${ }^{[13]}$ 亦揭示, 居住等建设用地对内涝灾害影响 最大, 而复杂的景观体系可降低内涝灾害。在用地 变化方面,彭建等 ${ }^{[14]}$ 指出建设用地的增加对暴雨洪 涝灾害风险具有不可忽视的影响。王玉金等 ${ }^{[15]}$ 利 用水文产流模型与经验方程模拟不同土地利用情 景下的城市积水, 发现城市化背景下迅速增加的硬 质用地加剧了内涝风险。Gori 等 ${ }^{[2]}$ 通过组合土地利 用预测和水文模拟方法, 指出土地利用变化会显著 增加城市滨水区域的洪涝风险。综合来看,城市扩 张和用地空间结构与布局的变化, 会导致不透水面 增加、地表径流峰值提高、雨水下渗减少, 从而引发 更为严重的内涝灾害 ${ }^{[16-17]}$ 。

在排水管网条件方面, 研究表明, 排水管网的 雨洪排泄能力与地表径流量、速度、峰值密切相关,

收稿日期: 2019-12-12; 修订日期: 2020-05-02。

基金项目: 国家社会科学基金项目(18BGL270)。[Foundation: National Social Science Founding of China, No. 18BGL270. ]

第一作者简介: 赵丽元(1984-), 女,江西南昌人,教授,主要从事可持续性城乡规划与设计研究。E-mail: liyuanzhao@hust.edu.cn 
不完备的排水管网设施会增加城市内涝风险。升 级排水管网标准与提升雨水储备能力, 已成为减少 和预防内涝的关键措施 ${ }^{[18-19]}$ 。同时, 作为量化城市 化强度和程度的关键要素, 不透水面密度也是重要

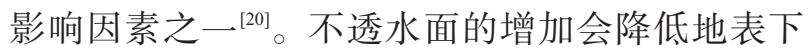
渗率和储水能力、增大径流速率, 进而增加内涝渍 水风险 ${ }^{[21-22]}$ 。

此外, 部分研究也揭示了人类活动侵占城市水 域对内涝灾害的影响。作为集水区的城市河湖水 域是洪水潜在的环境载体, 其蓄水量的改变将会直 接破坏地表径流的时空格局, 从而增加城市洪涝风 险。国外针对尼日利亚地区内涝灾害频发的原因 调查表明, 城市建设空间大量侵占了自然水体, 导 致河流形成瓶颈、雨季产生逆流, 是其内涝灾害的 主要原因 ${ }^{[23]}$ 。墨西哥地区的内涝风险研究证实, 湿 地的开发建设将大大增加城市洪涝风险 ${ }^{[4]}$ 。将水域 填占开发为不透水面的城市用地, 将直接造成水网 系统的连接阻塞,进而引发严重的洪涝灾害。

然而, 在城镇化进程快速推进和城市规划管控 滞后的双重背景下, 中国大部分城市都存在不同程 度的填湖造陆现象 ${ }^{[24-26]}$ 。中国学者针对这一现象与 内涝分布的关系进行了研究。李仁东等 ${ }^{[27]}$ 通过水 调节能力估算模型指出, 湖泊面积的减少会极大地 降低区域洪水调蓄能力, 从而提高内涝风险。曾忠 平等 ${ }^{[28]}$ 以武汉市南湖区域为研究对象, 将多时相遥 感影像图和新闻报道的内涝灾害点进行空间叠加 发现, $80 \%$ 以上的内涝点落在填湖造陆区域。

尽管已有研究证实了填湖造陆对内涝的影响, 但系统量化其影响程度并考虑未来空间开发策略 的内涝风险研究还较为缺乏。因此, 本文基于历史 遥感数据与内涝渍水实测数据, 通过构建二项 Logistic 模型, 定量研究城市建设及填湖造陆活动对内 涝风险的影响, 并进一步模拟预测不同用地开发策 略下的内涝风险及其空间分布, 针对不同用地类型 提出差异化的防洪排涝策略, 从而为低影响开发的 城市建设提供技术支撑。

\section{1 研究数据与方法}

\section{1 研究区域与数据来源}

武汉市跨长江发展, 全市下辖 13 个行政区, 其 中主城区包括 10 个行政区, 分别为江岸区、江汉区、 研口区、汉阳区、武昌区、洪山区、青山区、东西湖
区、蔡甸区、江夏区。本文选择武汉市主城区作为 研究区域(图 1), 主城区内湖网密布, 且地势低洼、暴 雨降水频繁, 以致内涝灾害频发 ${ }^{[10,29]}$ 。2016 年 7 月 武汉遭强降雨袭击, 城市内涝严重。连降 $7 \mathrm{~d}$ 的暴 雨导致全市 200 多处重要交通干道渍水, 受灾人口 多达 100 万, 直接经济损失 39.96 亿元。以武汉市主 城区为案例, 探讨城市建设活动对武汉市内涝灾害 的影响,并为城市规划实践提供防灾减灾对策具有 重要现实意义。

本文采用的数据包括 $30 \mathrm{~m}$ 分辨率的 Landsat 遥 感影像图、30 m 分辨率的数字高程模型(DEM)、土 地利用现状图、内涝渍水空间分布图及排水管网分 布图。其中, 遥感影像图包括 1984 年 8 月的 1 景 Landsat 4-5 MSS 影像数据, 以及 2017 年 7 月的 1 景 Landsat 8 OLI/TIRS 影像数据, 均通过中国科学院 计算机网络信息中心地理空间数据云平台(http:// www.gscloud.cn)下载获取, 用于识别自然水体的空 间变化状况。DEM 从美国地质调查局网站(http:// www.usgs.gov) 获取。武汉主城区2017年土地利用 现状图通过武汉市规划研究院获取, 用于提取影响 内涝渍水的城市建设因素。内涝渍水空间分布图 及排水管网分布图通过武汉市水务局获取,用于明 确一般和极端降水情景下的渍水空间分布、计算排 涝能力。文中所有图像统一采用WGS1984 地心坐 标系, 通用横轴墨卡托投影(Universal Transverse Mercator)。

通过采用 ENVI、CAD、ArcGIS 10.2 和 Matlab 2019a 等一系列工具进行数据读取、预处理, 以建立 研究所需数据库。ENVI用于解译遥感影像数据, 以提取用地分类信息。Matlab 2019a 中的图像处理 和数据分析工具则用于分析各城市建设因素与内 涝风险之间的关系。为与 $30 \mathrm{~m}$ 分辨率的历史遥感

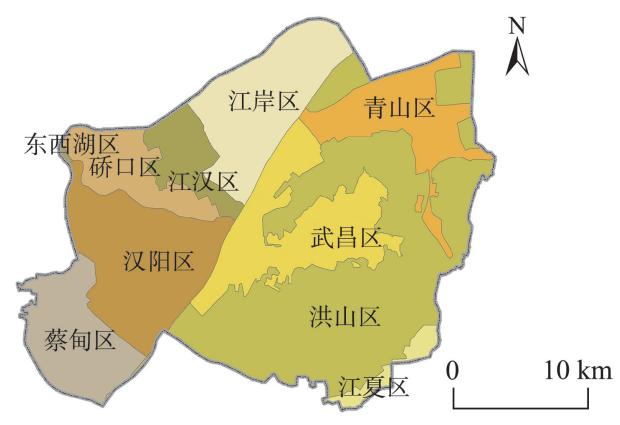

图 1 武汉市主城区区位及行政区划图

Fig.1 Location and administrative divisions of Wuhan City 
影像数据以及 DEM 数据相匹配, 本文将所有数据 转换为 $30 \mathrm{~m} \times 30 \mathrm{~m}$ 的栅格数据。 $30 \mathrm{~m}$ 属于中等分 辨率精度, 是当前遥感解译及土地覆被变化研究中 较常用的研究精度。该精度可较清晰表达本文研 究的渍水分布、用地类型等目标地物信息,可分辨 渍水及地类的较小图斑, 能够反映地图数据的基本 空间变化, 满足本文研究精度需要。研究区域划分 为 753334 个栅格, 其中每个栅格代表一个空间单元 对象, 记录存储数据的空间信息(如地理位置、用地 类型和洪涝风(险等)。在此样本数量条件下, Matlab 数据处理速率较快, 可以同时满足运算效率与结果 质量的需求。

\section{2 内涝渍水空间分布}

基于武汉市降水特征, 本文考虑 2 种情景下的 内涝渍水风险, 分别是: 一般降雨情景 $(24 \mathrm{~h} 95 \mathrm{~mm}$ ) 和极端降雨情景 $(24 \mathrm{~h} \sim 249 \mathrm{~mm})$ 。图 2 中的深蓝色 区域表示 2 种情景下武汉主城区内涝渍水的空间分 布。如图可见, 在一般降雨情景下, 渍水空间较少, 主要以散点状零星沿长江、汉江分布。而在极端降 雨情景下, 出现大面积的城市建设用地渍水, 且以 主城区中部及北部人口密集的江岸区、江汉区、研 口区受灾范围最广。

\section{3 水域时空变化分析}

由于城市建设活动加强, 武汉市水域空间被填 占现象严重。为直观地显示武汉城市空间增长对水 域(包括长江、汉江)的侵占情况, 将 1984年和 2017 年 的遥感影像图进行解译分类(图 3), 叠加 2017 年土地 利用现状图(图 4), 统计对比 33 a 间的用地变化(表 1), 揭示侵占水域的具体用地类型(图 5)。

由表 1 可见,与 1984 年相比, 2017 年武汉主城 区的建设面积增长迅猛, 增幅近 2 倍, 而水域和绿地 面积急剧减少。其中水域面积减少了 $30.68 \%$, 约以 平均每年 $1 \%$ 的速度被填占。通过叠加 $33 \mathrm{a}$ 间水域 被填占范围图与 2017 年土地利用现状图, 可以识别 出占用水域的具体用地类型。在被填占的水域面 积中, 仅 $18.93 \%$ 转变为绿地, 剩余 $81.07 \%$ 全部转化 成城市建设用地，包括居住用地、交通用地、商业用 地以及工业用地。其中, 转化成居住用地和交通用 地的面积占比最大, 分别达到 34.61\%和 $27.25 \%$ (图 5)。交通用地对水域的填占主要由武汉跨江发展、 湖泊众多的空间特征与城市交通发展的冲突导致; 而居住用地占比高则由其亲水性需求和住房商品 化的经济利益驱动双重原因引致 ${ }^{[30-31]}$ 。

\section{4 城市建设对内涝渍水空间分布影响的评估模型 构建}

对应于城市雨水的“排、蓄、渗、蒸发” 4 种排水 方式, 影响渍水空间分布的城市建设因素主要包 括: 地形地势、排水管网条件、地面不透水性、土地 利用类型以及填湖造陆活动 5 大类别。本文采用二 项 Logistic 模型来识别城市建设因素与内涝风险之 间的关系。该模型已被广泛应用于预测各类事件 发生的可能性,具有非线性的特征,在捕捉自然及 社会领域各要素间的非线性关系方面具备突出优 势 ${ }^{[32-33]}$ 。

二项 Logistic 模型由响应变量、解释变量及其 对应的回归系数构成。模型的响应变量遵循二项 式分布, 代表每一栅格是否发生内涝。模型中各解 释变量的重要性能通过回归系数体现,有助于分析 城市建设活动对内涝风险的影响程度。模型公式 可描述为:

$$
\begin{gathered}
u_{i}=\beta_{0}+\beta_{1} x_{i 1}+\beta_{2} x_{i 2}+\cdots+\beta_{j} x_{i j} \\
p_{i}=\frac{\exp \left(u_{i}\right)}{1+\exp \left(u_{i}\right)}
\end{gathered}
$$

式中: $u_{i}$ 代表用地栅格 $i$ 的效用函数, 即解释变量的 组合; $x_{i j}$ 代表第 $i$ 个用地栅格上的第 $j$ 种城市建设 活动因子; $p_{i}$ 是响应变量, 代表第 $i$ 个用地栅格上 的内涝风险; $\beta_{0} 、 \beta_{1} \cdots \cdots \beta_{j}$ 为需要标定的回归系数, 可定量描述各因子对内涝发生概率的作用和影响 强度; $\beta_{0}$ 为常数。

本文为解释变量的选择设定了 3 个原则, 即显 著性、高拟合优度和无多重共线性。通过迭代拟合 直到所有不符要求的变量被移除, 5 类城市建设因 素中的 8 项因子被挑选为最终的解释变量。首先, 地形地势因素包括高程 $\left(x_{1}\right)$ 以及邻域内海拔最低 $\left(x_{2}\right) 2$ 项因子。其中, “邻域” 由 $3 \times 3$ 的摩尔邻域空 间范围定义, 即“邻域内海拔最低”因子用于界定该 俩格具有其邻域 8 个栅格范围内的最低海拔。直观 而言, 海拔高度对雨洪的排蓄有重要影响, 某一空 间尺度的最低位置通常具有较高的洪水风险。其 次,考虑武汉排水管道的空间分布, 城市排水条件 可以由距排水管网的距离 $\left(x_{3}\right)$ 表示。为便于统计 分析, 距离数值通过自然断点法重分类为 3 个级 别。第三,地表不透水性 $\left(x_{4}\right)$ 是根据不同用地类型 的不透水率定义得到的, 道路、建设用地、绿地和水 体具备由高至低的不透水率, 因而被分别赋值为 3 、 
(a) 一般情景

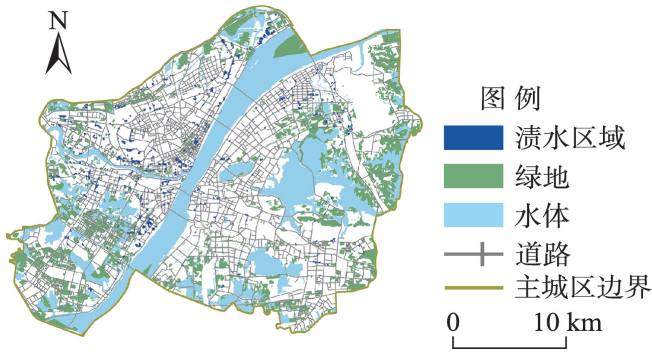

(b) 极端情景

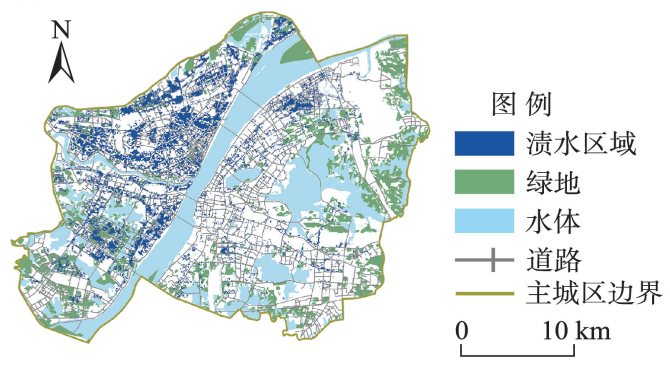

图 22 种降雨情景下的内涝渍水空间分布

Fig.2 Spatial distribution of flooding under two scenarios

(a) 1984年

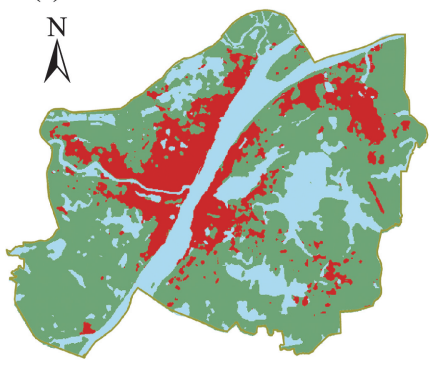

图 例

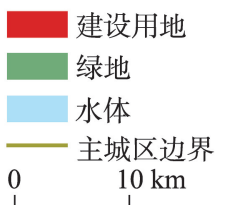

(b) 2017年

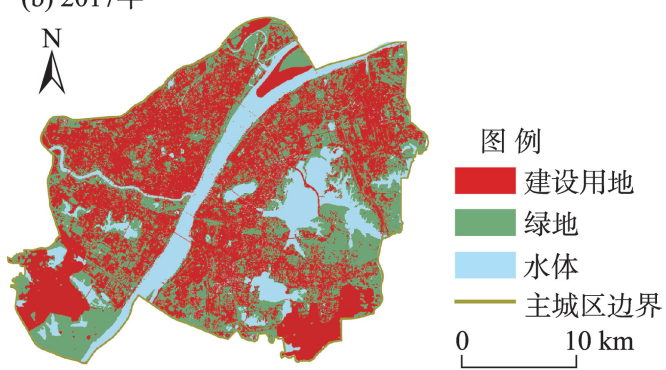

图 3 遥感影像图解译分类结果

Fig.3 Reclassification results of remote sensing data

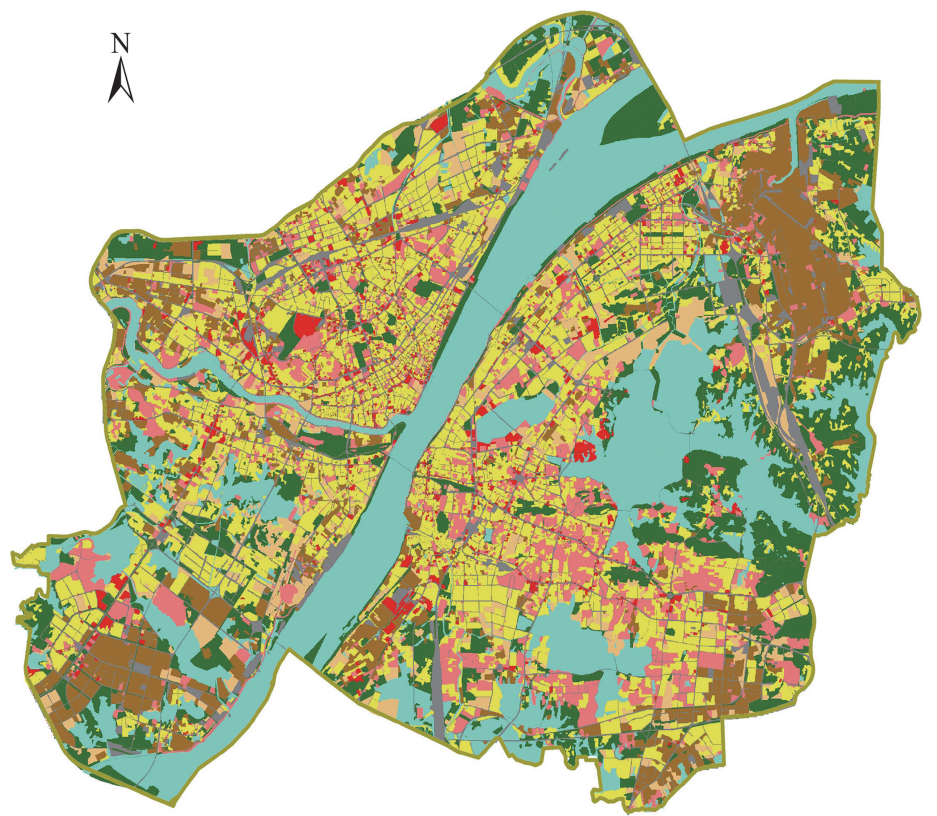

图例

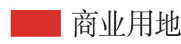

工业用地

公服用地

居住用地

交通用地

绿地

水体

非建设用地

$\Xi$ 武汉主城区边界

0

$10 \mathrm{~km}$

图 4 武汉市 2017 年土地利用现状

Fig.4 Land use types of Wuhan City, 2017

$2 、 1$ 和 0 。第四, $x_{5} 、 x_{6} 、 x_{7}$ 三项因子用于表示用地 类型, 包括是否为绿地棚格, 邻域内的绿地桖格数 量以及水体妌格数量。

具体数据内容如表 2 所示。

\section{2 模型结果与讨论}

\section{1 城市建设因素对内涝渍水空间分布的影响} 采用 ArcGIS 空间分析与 Matlab 2019 统计工 
表 1 武汉市主城区 1984-2017年土地利用变化

Tab.1 Land use changes in Wuhan City, 1984-2017

\begin{tabular}{cccc}
\hline 年份 & 建设用地 $/ \mathrm{km}^{2}$ & 绿地 $/ \mathrm{km}^{2}$ & 水体 $/ \mathrm{km}^{2}$ \\
\hline 1984 & 122.84 & 397.05 & 170.90 \\
2017 & 364.09 & 208.23 & 118.47 \\
变化 $^{*}$ & +241.25 & -188.82 & -52.42 \\
\hline
\end{tabular}

注: *表示以 1984 年为基准年, 2017 年用地变化情况,增加用 “+”表示,减少用“-”表示。

具, 对一般降雨情景与极端降雨情景下的 Logistic 模型进行回归分析。采用最小二乘法对回归参数 进行标定,得到城市建设因素对内涝渍水空间分布 的影响。2 种情景所涉及的解释变量一致,但拟合 的响应变量分别为一般降雨情景和极端降雨情景
渍水分布图(图 2)。为确保样本数据的科学合理性, 回归样本数据包含全部渍水用地栅格与等数量的 非渍水用地㮽格。其中, 非渍水用地栅格样本采用 Monte Carlo 方法进行随机选取 ${ }^{[34]}$ 。Monte Carlo 方 法是通过统计模拟来选择样本数据的随机方法, 可 通过对每个统计模拟的估计样本求平均来获得稳 定的样本数据。由此选取的一般和极端降雨 2 种情 景下的回归样本栅格数量分别为 25846 和 145022 个。

在变量取值方面,表 2 中的 8 项解释变量均归 一化至 $[0,1]$ 区间,以消除量纲不一致对统计分析的 影响。响应变量由 2 个情景下实际渍水的空间分布 图生成, 若栅格 $i$ 渍水, 则 $p_{i}$ 赋值为 1 , 否则赋值为 (a) 面积统计

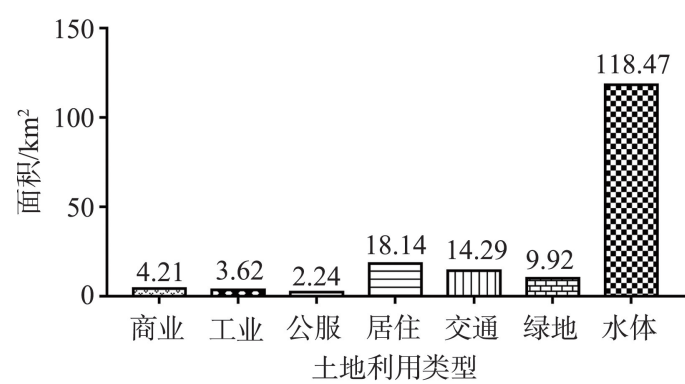

(b) 占比统计

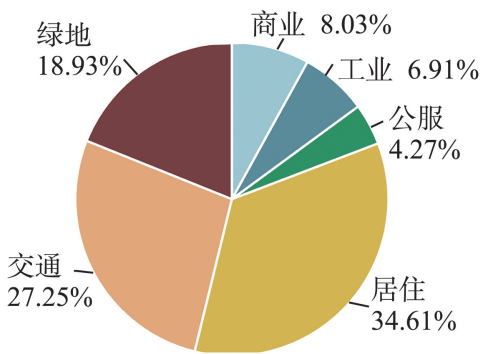

图 5 1984-2017年各用地填湖造陆状况统计

Fig.5 Statistics of land conversion from water area, 1984-2017

表 2 城市建设因素指标体系

Tab.2 Indicators of urban development and their descriptive statistics

\begin{tabular}{|c|c|c|c|c|c|}
\hline \multirow{2}{*}{ 因素分类 } & \multirow{2}{*}{ 解释变量 } & \multicolumn{3}{|c|}{ 数据统计分析 } & \multirow{2}{*}{ 数据量解释 } \\
\hline & & 取值范围 & 平均值 & 标准差 & \\
\hline \multirow[t]{2}{*}{ 地形地势因素 } & 高程 $\left(x_{1}\right)$ & {$[-5,101]$} & 27.338 & 7.899 & 栅格实际高程数值 \\
\hline & 邻域内海拔最低 $\left(x_{2}\right)$ & {$[0,1]$} & 0.103 & 0.305 & $\begin{array}{l}\text { 若Moore 邻域内该栅格海拔最低, 值为 } 1 \text {; } \\
\text { 若Moore 邻域内该栅格海拔非最低, 值为 } 0\end{array}$ \\
\hline 排水管网条件 & 距排水管网距离 $\left(x_{3}\right)$ & {$[1,3]$} & 1.944 & 0.830 & $\begin{array}{l}0 \leqslant \text { 距离 } \leqslant 30 \mathrm{~m} \text {, 值为 } 3 ; \\
30 \mathrm{~m}<\text { 距离 } \leqslant 100 \mathrm{~m} \text {, 值为 } 2 ; \\
100 \mathrm{~m}<\text { 距离, 值为 } 1\end{array}$ \\
\hline 地表不透水性 & 各类用地不透水率 $\left(x_{4}\right)$ & {$[0,3]$} & 0.622 & 1.066 & $\begin{array}{l}\text { 道路不透水率, 值为 } 3 ; \\
\text { 建设用地不透水率, 值为 } 2 ; \\
\text { 绿地不透水率, 值为 } 1 ; \\
\text { 水域不透水率, 值为 } 0\end{array}$ \\
\hline \multirow[t]{3}{*}{ 土地利用类型 } & 栅格用地类型为绿地 $\left(x_{5}\right)$ & {$[0,1]$} & 0.171 & 0.377 & $\begin{array}{l}\text { 栅格为绿地类型, 值为 } 1 ; \\
\text { 栅格不是绿地类型, 值为 } 0\end{array}$ \\
\hline & 邻域绿地栅格数 $\left(x_{6}\right)$ & {$[1,8]$} & 1.360 & 2.704 & $\begin{array}{l}\text { Moore 邻域中绿地栅格的个数: 值为 } 1 \text { 至 } 8 \\
\text { 的整数 }\end{array}$ \\
\hline & 邻域水体栅格数 $\left(x_{7}\right)$ & {$[1,8]$} & 0.721 & 2.106 & $\begin{array}{l}\text { Moore 邻域中水栅格的个数: 值为 } 1 \text { 至 } 8 \text { 的 } \\
\text { 整数 }\end{array}$ \\
\hline 填湖造陆因素 & $\begin{array}{l}1984-2017 \text { 年间被填占 } \\
\text { 的水域栅格 }\left(x_{8}\right)\end{array}$ & {$[0,2]$} & 0.033 & 0.178 & $\begin{array}{l}\text { 未填湖非水域的栅格,值为 } 0 ; \\
\text { 水域转绿地的栅格,值为 } 1 ; \\
\text { 水域转城市建设用地的栅格,值为 } 2\end{array}$ \\
\hline
\end{tabular}


0 。将各变量的样本数据代人模型, 通过最小二乘 法计算得到等式(1)中的回归系数 $\beta_{j}$ 。2 种情景下 的参数回归结果如表 3 所示, 所有回归系数的 $P$ 统 计值都在 $1 \%$ 以内, 统计显著性高, 显示模型具有良 好的拟合效果。模型的回归参数能够定量地捕捉 各因素与渍水风险的关系。

地形地势因素统计结果中, 一般与极端降雨情 景的高程回归参数分别为 -0.521 和 1.990 , 表明一般 降雨情况下, 高程越高的地方, 被淹没风险越小; 而 极端降雨情况下, 高程高的地方也有较大的淹没风 险。通过对比遥感影像图和数字高程地图, 可以发 现武汉市整体海拔偏低、坡度平缓, 因而大幅减缓 了地面的径流运动,使得较高海拔地区在极端降雨 的情形下也易出现渍水。邻域内海拔最低因子回 归结果的正向系数表明, 若该栅格为邻域内海拔最 低,则渍水风险高。

排水管网条件统计结果中, 2 个情景下 “距排水 管网距离因子” 的回归系数分别为 -1.378 和 -1.385 , 均为显著负相关。一般降雨情景的回归系数预示 着每接近排水管网 1 个单位的距离,渍水的风险就 会增加 1.378 个单位。这意味着到道路排水管道距 离越近, 被淹没风险越高。其原因可以解释为: 一 方面, 因排水的需要, 排水管口通常属于邻域范围 内地势较低的区域, 因此容易渍水 ${ }^{[35-36]}$; 另一方面也 反映了武汉主城区的排水管网设施不足,在降雨期 间易出现排水倒灌现象, 导致逢雨淹路现象严重。 为应对长时地表强径流带来的内涝威胁, 提升排水 设施系统的洪水排泄能力十分必要。
地表不透水性因素统计结果中, 2 个情景下“用 地不透水性” 因子的回归系数分别为 3.112 与 1.380 ,均为显著正相关。量化验证了城市化进程中 不透水面的增加会加剧城市内涝的风险, 与既有的 研究结论一致 ${ }^{[3]}$ 。土地利用属性因素统计结果中, “用地类型为绿地”因子的负值回归系数表明,相比 建设用地, 具备透水表面的绿地栅格渍水风险较 低。然而, “邻域绿地栅格数”的正值回归系数显示 现状渍水的高风险建设用地, 往往周边绿地较多。 绿地是雨洪的重要载体, 与大面积绿地毗邻的栅格 会有较高的渍水风险。此外, “邻域水体栅格数”因 子与渍水风险的正相关关系, 表明滨水空间的渍水 可能性较其他用地高, 这与内涝渍水的现状空间分 布(图2)相吻合。

特别地, “填湖造陆用地” 因素的回归参数分别 是-0.202与 0.116 , 即填湖造陆用地在一般降雨情景 下与渍水风险呈显著负相关, 而极端降雨情景下呈 显著正相关。这是由于一般降雨情景下仅产生少 量的地表径流, 此时填湖造陆用地的渍水风险并不 比常规陆地风险高。但在极端降雨情况下,地表雨 洪径流大幅增加，建设用地的填占导致湖泊水体的 蓄洪能力下降, 滨水的填湖造陆用地渍水风险则相 对提升,往往成为被淹没的对象。该结果表明填湖 造陆在极端降雨情景下, 将成为加剧城市内涝的重 要因素。

\section{2 内涝灾害风险分布图预测}

内涝灾害风险分布图可以通过识别不同降雨 情景下各地块的内涝风险程度, 确定防灾措施的优

表 32 种降雨情景下二项 Logistic 回归结果

Tab.3 Logistic regression results for two rainfall scenarios

\begin{tabular}{|c|c|c|c|c|c|c|c|}
\hline & \multirow[t]{2}{*}{ 解释变量 } & \multicolumn{3}{|c|}{$\begin{array}{c}\text { 一般情景 } \\
(24 \mathrm{~h} \text { 95 mm) }\end{array}$} & \multicolumn{3}{|c|}{$\begin{array}{c}\text { 极端情景 } \\
(24 \text { h 249 mm) }\end{array}$} \\
\hline & & 回归系数 & $t$ 统计量 & $P$ 值 & 回归系数 & $t$ 统计量 & $P$ 值 \\
\hline \multirow[t]{2}{*}{ 地形地势因素 } & 高程 $\left(\beta_{1}\right)$ & -0.521 & -2.616 & $* * *$ & 1.990 & 22.944 & $* * *$ \\
\hline & 邻域内海拔最低 $\left(\beta_{2}\right)$ & 0.188 & 3.924 & $* * *$ & 0.086 & 4.500 & $* * *$ \\
\hline 排水管网条件 & 距排水管网距离 $\left(\beta_{3}\right)$ & -1.378 & -25.268 & $* * *$ & -1.385 & -61.811 & $* * *$ \\
\hline 地表不透水性 & 各类用地不透水性 $\left(\beta_{4}\right)$ & 3.112 & 11.299 & $* * *$ & 1.380 & 14.697 & $* * *$ \\
\hline \multirow[t]{3}{*}{ 土地利用类型 } & 栅格用地类型为绿地 $\left(\beta_{5}\right)$ & -2.224 & -10.984 & $* * *$ & -1.104 & -15.798 & $* * *$ \\
\hline & 邻域绿地栅格 $\left(\beta_{6}\right)$ & 2.076 & 8.602 & $* * *$ & 3.866 & 41.569 & $* * *$ \\
\hline & 邻域水体栅格数 $\left(\beta_{7}\right)$ & 1.865 & 14.908 & $* * *$ & 1.233 & 26.057 & $* * *$ \\
\hline 填湖造陆因素 & $\begin{array}{l}1984-2017 \text { 年间被填占的 } \\
\text { 水域栅格 }\left(\beta_{8}\right)\end{array}$ & -0.202 & -2.601 & $* * *$ & 0.116 & 5.902 & $* * *$ \\
\hline
\end{tabular}

注:***表示显著性水平为 $1 \%$ 。 
先级别, 可为灾害应对策略及相关规划的制定提供 参考。基于上述城市建设因素对渍水空间分布影 响的标定结果, 本文采用 ArcGIS 空间分析工具与 Matlab 模拟仿真技术, 对 2 种用地空间布局策略进 行内涝灾害风险分布模拟。用地策略 I 为现状城市 建设用地空间分布基准模式, 用地策略 II 为假设所 有绿地及非建设用地栅格都变为建设用地的极端 用地开发模式。具体模拟方法为: 首先, 根据 2 种用 地策略的空间布局,更新式(1)中的 5 类城市建设变 量; 其次, 基于标定的二项 Logistic 模型, 将 2 种用地 策略的城市建设相关变量及对应的标定系数代人 式(2), 计算得到不同开发模式下各栅格的城市内涝 风险预测结果。图6显示了一般与极端降雨 2 种情 景下, 不同用地开发策略的城市内涝风险空间分布 图。为可视化风险程度, 利用ArcGIS 的自然断点法 将渍水风险划定为 7 个等级, 等级越高, 风险越高。

由图可见, 极端降雨情景(图 6c、6d)渍水风险明 显高于一般情景(图 6a、6b)。在一般情景中, 武汉市 主城区大部分区域的渍水风险都在 3 级以下, 仅有 少量滨水区域承担较高的渍水风险, 且中部地势较 高的建设用地渍水风险较低。相比之下, 极端情景 的预测结果显示, 主城区中部的大片区域将面临较 高的渍水风险, 尤其在图 $6 \mathrm{~d}$ 中, 大量的滨水区有被 淹没的风险。

在各类降雨情景中, 用地策略 II (图 6b、6d)的渍 水风险明显高于用地策略 I(图 6a、6c)。渍水风险模 拟的结果进一步说明, 绿地及非建设用地的开发建 设将加剧城市内涝的风险。这预示了当前迫切需 要制定相关的空间用途管制规划, 以严控各项建设 活动在高内涝风险用地中的开展, 从规划源头预防 城市内涝风险导致的危害。

\section{3 城市内涝防治建议}

适宜的应对策略有助于降低内涝灾害的危 害。对于大尺度的城市建成区而言, 不同用地类型 应采取不同的防灾减灾策略, 以确保因地制宜地提 升用地防灾的能力 ${ }^{[1]}$ 。在《城市用地分类与规划建 设用地标准(GB50137-2011)》所划定的用地大类 基础上, 根据内涝防治策略的差异性, 针对用地的 硬化程度、开发强度、布局特征、排涝设施基础等不 同特性, 本文将用地分为 4 大类: I 类用地, 包括道路 与交通设施用地; II 类用地, 包括居住用地、公共管 理与公共服务用地、商业服务业设施用地、物流仓 储用地、公用设施用地; III 类用地,包括工业用地;
IV 类用地,包括绿地与广场用地、非建设用地。将 内涝灾害风险分布预测图与土地利用现状图叠加, 可得到具有高内涝风险的用地范围, 见图 7 所示(对 应图 6 风险等级为 6.7 的空间范围)。一般降雨情 景中, 2 种用地策略下高风险的城市建设用地分布 较少(图 7a、7b)。而在极端降雨情景中(图 7c、7d), 特别是用地策略 II 中(图 7d), 大量现状绿地及非建 设用地将面临高等级渍水风险。在制定城市建设 控制规划的过程中,可将极端降雨情景下的绿地及 非建设用地范围作为管控的参考范围。

图 7 中, 4 类用地的内涝风险防治策略应各有 侧重。首先, 对风险高的城市道路与交通设施用地 (I类), 需合理优化其地下敷设的排水系统布局, 加 强管网建设,强化排水应急管理。其次, 针对渍水 风险高的居住、商业、物流和公服设施用地(II 类), 可采用敷设透水铺装, 并借鉴低影响开发理念的雨 水花园、屋顶绿化模式, 以吸收储存雨水并缓解地 表径流。通过推广韧性社区的建设,逐步提升居住 及公服用地的防灾、抗灾能力。第三,针对渍水风 险高的工业用地(III 类), 应充分考虑对既有雨水调 蓄和回收循环设施的利用。工业用地具有连片布 局的特点,适宜布局具有高效雨洪处理能力的大型 设备, 可资源化利用雨水、减少雨水径流及外排量, 以减轻雨水管渠的排涝压力, 降低内涝风险。最 后, 针对渍水风险高的绿地、非建设用地(IV 类), 应 限制开发且制定相关控制指标, 防止对湖泊、绿地 和其他未利用地进行过度开发和不当开发, 保障自 然水体及绿地对雨洪的下渗和储藏能力, 采取源头 控制的方法来避免或降低灾害导致的人力、财产损 失。通过提升排水系统的排泄能力、扩大地表水下 渗量、增强雨水储存能力、充分循环利用雨水资源、 减少地表径流量, 可有效预防和减轻城市涝灾的 影响。

\section{3 结论}

本文以武汉市主城区为实证案例, 通过历史遥 感影像图对比提取填湖造陆活动范围, 采用二项 Logistic 回归分析模型量化城市建设因素和填湖造 陆活动对内涝空间分布的影响,并模拟不同用地开 发模式下武汉市主城区的内涝风险分布, 为城市内 涝灾害风险管理提供直观的辅助决策依据。主要 结论如下: 
(a) 一般情景下策略I结果

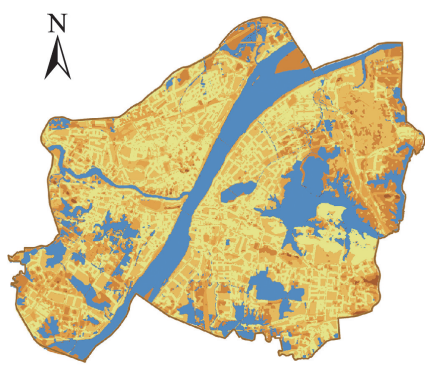

(c) 极端情景下策略I结果

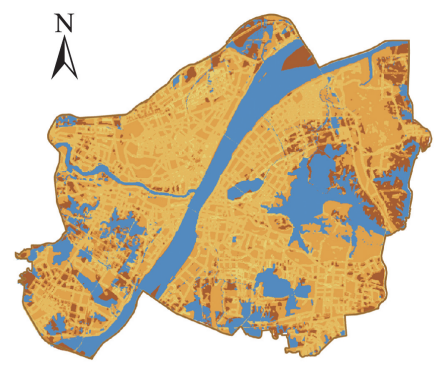

风险等级

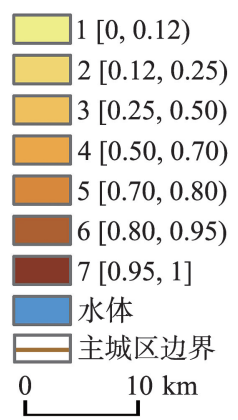

风险等级

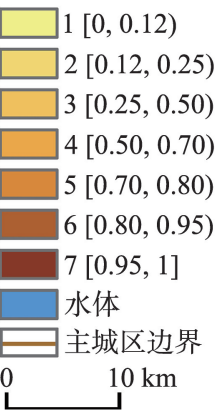

(b) 一般情景下策略II结果

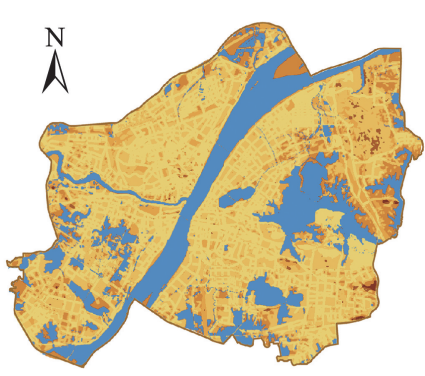

(d) 极端情景下策略II结果

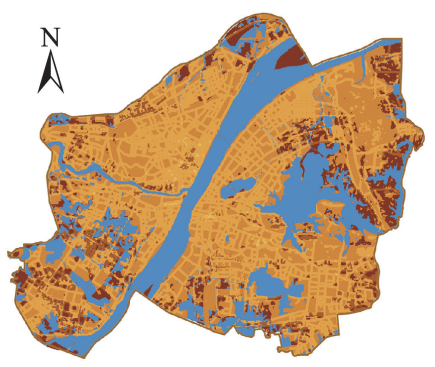

风险等级

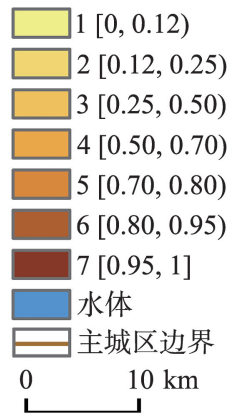

风险等级

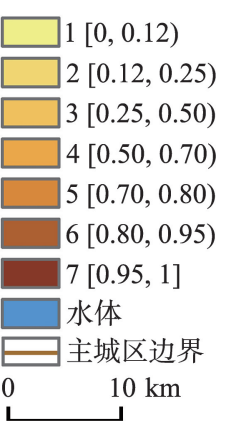

图 6 不同降雨情景下的 2 种用地策略内涝风险

Fig.6 Spatial distribution of flooding risk for two strategies under the regular and extreme scenarios

(a) 一般情景下策略I结果

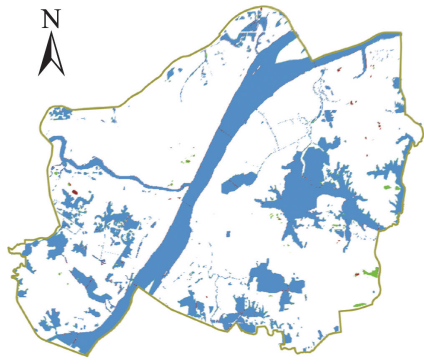

(c) 极端情景下策略I结果

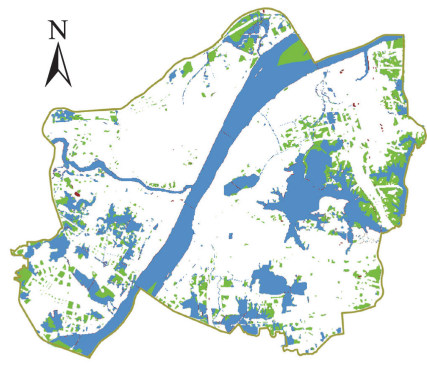

图例

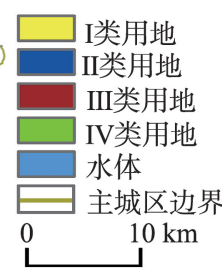

图例

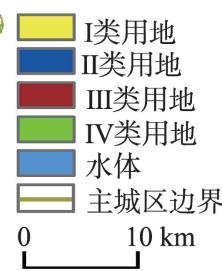

(b) 一般情景下策略II结果

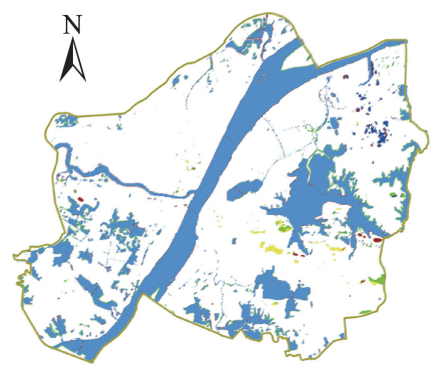

图 例

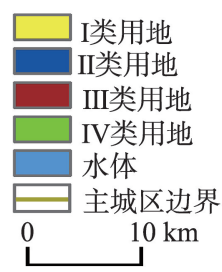

(d) 极端情景下策略II结果

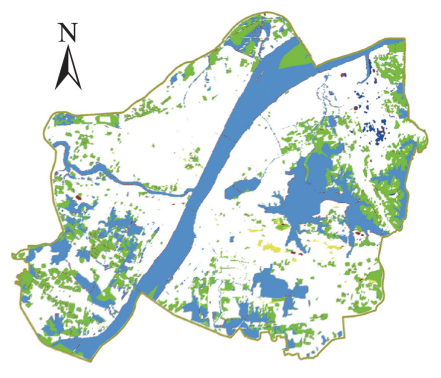

图例

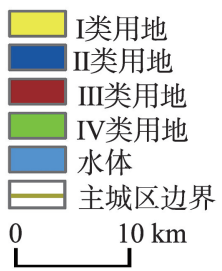

图 7 内涝高风险用地空间分布

Fig.7 Spatial distribution of four types of land use at high risk of flooding 
(1) 武汉市建设用地填占自然水体现象严峻。 1984-2017年,武汉市主城区有超过 30\%的自然水 体被填占开发。被填占水体中有 $81.07 \%$ 转化为城 市建设用地, 其中又以居住用地和交通用地的面积 占比最大,分别达到 $34.61 \%$ 和 $27.25 \%$ 。

(2) 回归模型结果表明,地形地势、排水管网条 件、地表不透水性、摩尔邻域内用地结构都与城市 渍水有显著相关性。此外, 在极端降雨情景下, 填 湖造陆将成为加剧其周边用地内涝的重要因素。

(3) 内涝风险分布模拟结果显示, 在绿地、非建 设用地均转化为建设用地的极端用地开发模式下， 城市内涝风险将急剧提升。当前迫切需要在考虑 灾害风险、环境承载力的基础上制定各类空间用途 管制规划, 严控建设活动在高内涝风险用地中的开 展, 从规划源头开展城市内涝风险的防控工作。

(4) 针对不同用地类型的特性, 应采用差异化 的内涝防治策略。道路交通用地应注重优化其地 下敷设排水管网的布局、提升排洪能力; 居住、商业 和公服设施用地应实践低影响开发理念, 采用雨水 花园、屋顶绿化等海绵城市雨洪管理技术提升社区 韧性; 工业用地可布局大型雨洪循环处理设备, 降 低雨水管渠排涝压力; 应防止湖泊、绿地及其他未 利用地的过度开发, 保障自然下渗和储藏能力。

需要指出的是, 各项城市建设因子与内涝风险 之间的关系是复杂的、非稳态的,需要在未来的研 究中引人地理加权回归方法展开更进一步的分 析。除本文已考虑的因素之外, 内涝缓解与应急管 理能力也是影响城市内涝的重要因素 ${ }^{[7]}$ 。因此, 有 必要在模型构建过程中将内涝的持续时间纳人考 量, 以更精确地量化评估内涝灾害的影响程度。尽 管存在以上局限性, 本文所构建的模型尝试模拟城 市建设活动带来的影响, 可为内涝防治规划的编制 和低影响开发规划提供依据和支撑, 同时为海绵城 市的规划建设和方案优化提供决策支持。

\section{参考文献(References)}

[1] Louise B, Karin W, Isadora D M T, et al. Urban flood resilience: A multi-criteria index to integrate flood resilience into urban planning [J]. Journal of Hydrology, 2019, 573 (6): 970-982.

[2] Gori A, Blessing R, Juan A, et al. Characterizing urbanization impacts on floodplain through integrated land use, hydrologic, and hydraulic modeling $[\mathrm{J}]$. Journal of Hydrology, 2019, 568(1): 82-95.
[3] Murali R M, Kumar P K D. Implications of sea level rise scenarios on land use/land cover classes of the coastal zones of Cochin, India [J]. Journal of Environmental Management, 2015, 148(1): 124-133.

[4] Rasanen A, Nygren A, Monge A M, et al. From divide to nexus: Interconnected land use and water governance changes shaping risks related to water [J]. Applied Geography, 2018, 90(1): 106-114.

[5] Brody S D, Gunn J, Peacock W, et al. Examining the influence of development patterns on flood damages along the gulf of Mexico [J]. Journal of Planning Education \& Research, 2011, 31(4): 438-448.

[6] Abebe Y A, Ghorbani A, Nikolic I, et al. A coupled floodagent-institution modelling (CLAIM) framework for urban flood risk management [J]. Environmental Modelling \& Software, 2019, 111(1): 483-492.

[7] Lee Y, Brody S D. Examining the impact of land use on flood losses in Seoul, Korea [J]. Land Use Policy, 2018, 70(1): 500-509.

[8] Mileti D S, Gailus J L. Sustainable development and hazards mitigation in the United States: Disasters by design revisited $[\mathrm{J}]$. Mitigation and Adaptation Strategies for Global Change, 2005, 10(3): 491-504.

[9] Diakakis M, Deligiannakis G, Pallikarakis A, et al. Factors controlling the spatial distribution of flash flooding in the complex environment of a metropolitan urban area: The case of Athens 2013 flash flood event [J]. International Journal of Disaster Risk Reduction, 2016, 18(9): 171180.

[10] Liu J, Shi Z W. Quantifying land-use change impacts on the dynamic evolution of flood vulnerability [J]. Land Use Policy, 2017, 65(6): 198-210.

[11] Perezmolina E, Sliuzas R V, Flacke J, et al. Developing a cellular automata model of urban growth to inform spatial policy for flood mitigation: A case study in Kampala, Uganda $[\mathrm{J}]$. Computers, Environment and Urban Systems, 2017, 65(9): 53-65.

[12] Lennon M, Scott M, O'Neill E. Urban design and adapting to flood risk: The role of green infrastructure $[\mathrm{J}]$. Journal of Urban Design, 2014, 19(5): 745-758.

[13] 吴健生, 张朴华. 城市景观格局对城市内涝的影响研 究: 以深圳市为例 [J]. 地理学报, 2017, 72(3): 444-456. [Wu Jiansheng, Zhang Puhua. The effect of urban landscape pattern on urban waterlogging. Acta Geographica Sinica, 2017, 72(3): 444-456. ]

[14] 彭建, 魏海, 武文欢, 等. 基于土地利用变化情景的城市 暴雨洪涝灾害风险评估: 以深圳市茅洲河流域为例 [J]. 生态学报, 2018, 38(11): 3741-3755. [Peng Jian, Wei 
Hai, Wu Wenhuan, et al. Storm flood disaster risk assessment in urban area based on the simulation of land use scenarios: A case of Maozhou Watershed in Shenzhen City. Acta Ecologica Sinica, 2018, 38(11): 3741-3755. ]

[15] 王玉金金, 曾燕, 邱新法, 等. 土地利用变化对城市积涝的 影响研究: 以南京市浦口区为例 [J]. 气象科学, 2017, 37(2): 231-238. [Wang Yuxin, Zeng Yan, Qiu Xinfa, et al. Impact of land use change on urban waterlogging: Case of Nanjing Pukou. Journal of the Meteorological Sciences, 2017, 37(2): 231-238. ]

[16] Kumar D S, Arya D S, Vojinovic Z. Modeling of urban growth dynamics and its impact on surface runoff characteristics $[\mathrm{J}]$. Computers Environment and Urban Systems, 2013, 41(1): 124-135.

[17] Niehoff D, Fritsch U, Bronstert A. Land-use impacts on storm- runoff generation: Scenarios of land- use change and simulation of hydrological response in a meso-scale catchment in SW-Germany [J]. Journal of Hydrology, 2002, 267(1): 80-93.

[18] Bazin P, Nakagawa H, Kawaike K, et al. Modeling flow exchanges between a street and an underground drainage pipe during urban floods [J]. Journal of Hydraulic Engineering, 2014, 140(10): 04014051. doi: 10. 1061/(ASCE) HY. 1943-7900. 0000917.

[19] Djordjević S, Prodanović D, Maksimović C, et al. SIPSON- simulation of interaction between pipe flow and surface overland flow in networks $[\mathrm{J}]$. Water Science \& Technology, 2005, 52(5): 275-283.

[20] Jovanovic T, Mejía A, Gall H, et al. Effect of urbanization on the long-term persistence of streamflow records [J]. Physica A: Statistical Mechanics \& Its Applications, 2016, 447(4): 208-221.

[21] Brun S E, Band L E. Simulating runoff behavior in an urbanizing watershed $[\mathrm{J}]$. Computers Environment \& Urban Systems, 2000, 24(1): 5-22.

[22] Weng Q H. Modeling urban growth effects on surface runoff with the integration of remote sensing and GIS [J]. Environmental Management, 2001, 28(6): 737-748.

[23] Israel A O. Nature, the built environment and perennial flooding in Lagos, Nigeria: The 2012 flood as a case study [J]. Urban Climate, 2017, 21(9): 218-231.

[24] Lang Y Q, Song W, Deng X Z. Projected land use changes impacts on water yields in the karst mountain areas of China [J]. Physics and Chemistry of the Earth, Parts A/B/ C, 2018, 104(4): 66-75.

[25] Sun Z X, Wu F, Shi C C, et al. The impact of land use change on water balance in Zhangye City, China [J]. Physics \& Chemistry of the Earth, Parts A/B/C, 2016, 96
(12): 64-73.

[26] Xie Linjun, Flynn A, Tan-Mullins M, et al. Water and land: Environmental governance and Chinese eco-development [J]. Journal of Cleaner Production, 2019, 221(6): 839-853.

[27] 李仁东. 土地利用变化对洪水调蓄能力的影响: 以洞庭 湖区为例 [J]. 地理科学进展, 2010, 23(6): 90-95, 115116. [Li Rendong. The impact of the land use change on the floodwater adjustment and storage: A case study on the Dongting Lake area. Progress in Geography, 2010, 23 (6): 90-95, 115-116. ]

[28] 曾忠平, 彭浩轩. 城市湿地损失和内涝灾害响应的遥感 分析: 以武汉市南湖为例 [J]. 长江流域资源与环境, 2018, 27(4): 929-938. [Zeng Zhongping, Peng Haoxuan. Remote sensing analysis of urban wetland loss and waterlogging: A case of Wuhan South Lake. Resources and Environment in the Yangtze Basin, 2018, 27(4): 929-938. ]

[29] Jiang Y, Zevenbergen C, Ma Y C. Urban pluvial flooding and stormwater management: A contemporary review of China's challenges and "sponge cities" strategy [J]. Environmental Science \& Policy, 2018, 80(2): 132-143.

[30] Wen H Z, Bu X Q, Qin Z F, et al. Spatial effect of lake landscape on housing price: A case study of the West Lake in Hangzhou, China [J]. Habitat International, 2014, 44: 31-40.

[31] Yang Y C, Zhang D L, Meng Q M, et al. Stratified evolution of urban residential spatial structure in China through the transitional period: A case study of five categories of housings in Chengdu [J]. Habitat International, 2017, 69(7): 78-93.

[32] Sado-Inamura Y, Fukushi K. Empirical analysis of flood risk perception using historical data in Tokyo $[\mathrm{J}]$. Land Use Policy, 2019, 82(3): 13-29.

[33] Zhao L Y, Peng Z R. LandSys: An agent-based Cellular Automata model of land use change developed for transportation analysis [J]. Journal of Transport Geography, 2012, 25(11): 35-49.

[34] Kroese D P, Brereton T, Taimre T, et al. Why the Monte Carlo method is so important today [J]. Wiley Interdisciplinary Reviews Computational Statistics, 2014, 6: 386392.

[35] Emilia K. The interaction between road traffic safety and the condition of sewers laid under roads [J]. Transportation Research Part D: Transport \& Environment, 2016, 48 (10): 203-213.

[36] Zischg J, Rogers B, Gunn A, et al. Future trajectories of urban drainage systems: A simple exploratory modeling approach for assessing socio-technical transitions [J]. Sci- 
ence of the Total Environment, Part 2, 2019, 651(2): 1709-1719.

[37] Leandro J, Schumann A, Pfister A. A step towards consid- ering the spatial heterogeneity of urban key features in urban hydrology flood modeling [J]. Journal of Hydrology, 2016, 535(4): 356-365

\title{
Impact of urban development on the risk of flooding: A case study of Wuhan City, China
}

\author{
ZHAO Liyuan, WEI Jialing \\ (School of Architecture and Urban Planning, Huazhong University of Science and Technology, \\ Wuhan 430074, China)
}

\begin{abstract}
Urban pluvial flooding is an increasing problem for cities worldwide. Urban spatial growth and development have been widely recognized as one of the most important contributors to the increasing risk of flood disasters. Using Wuhan City, China as a case, this study developed a binary Logistic model to quantify the impacts of urban development on flooding under different rainfall scenarios (regular and extreme), especially the role of land conversion from water areas. Based on historical remote sensing data, the analysis of the dynamic land use changes indicates that over 30\% of water areas had been converted into urban construction lands from 1984 to 2017. The results show that the conversion of water areas severely intensified the flooding risk of the surrounding locations in the extreme rainfall scenario. In addition to this land conversion, elevation, drainage conditions, land use types, and land use of surrounding areas are also significantly correlated with urban flooding. Based on two land use and development strategies, the risk maps of future flooding were predicted under regular and extreme rainfall scenarios. These maps show that the development of the remaining vacant lands will induce even worse flooding. Adaptation strategies corresponding to different land use types are provided according to the predicted flooding risks. The model could help develop adaptation strategies and policies to cope with future urban flooding by exploring its driving factors.
\end{abstract}

Keywords: urban flooding; spatial distribution; urban construction; binary Logistic model 